\title{
Detection of Ganoderic Acid A in Ganoderma lingzhi by an Indirect Competitive Enzyme-Linked Immunosorbent Assay
}

Authors

Affiliations

Seiichi Sakamoto $^{1 *}$, Toshitaka Kohno ${ }^{1 *}$, Kuniyoshi Shimizu ${ }^{2}$, Hiroyuki Tanaka ${ }^{1}$, Satoshi Morimoto

${ }^{1}$ Department of Pharmacognosy, Graduate School of Pharmaceutical Sciences, Kyushu University, Higashi-ku, Fukuoka, Japan

${ }^{2}$ Department of Agro-Environmental Sciences, Graduate School of Agriculture, Kyushu University, Higashi-ku, Fukuoka, Japan

Key words

- Ganoderma lingzhi

- Ganodermataceae

- enzyme-linked immunosorbent assay

- ganoderic acid $A$ (GAA)

- monoclonal antibody

- quality control

\section{Abstract \\ $\nabla$}

Ganoderma is a genus of medicinal mushroom traditionally used for treating various diseases. Ganoderic acid A is one of the major bioactive Ganoderma triterpenoids isolated from Ganoderma species. Herein, we produced a highly specific monoclonal antibody against ganoderic acid A (MAb $12 \mathrm{~A}$ ) and developed an indirect competitive ELISA for the highly sensitive detection of ganoderic acid A in Ganoderma lingzhi, with a limit of detection of $6.10 \mathrm{ng} / \mathrm{mL}$. Several validation analyses support the accuracy and reliability of the developed indirect competitive ELISA for use in the quality control of Ganoderma based on ganoderic acid A content. Furthermore, quantitative analysis of ganoderic acid A in G. lingzhi revealed that the pileus exhibits the highest ganoderic acid $A$ content compared with the stipe and spore of the fruiting

\section{Introduction}

received Nov. 8, 2015

revised February 16, 2016

accepted February 24, 2016

Bibliography

Dol http://dx.doi.org/

10.1055/s-0042-104202

Published online April 19, 2016

Planta Med 2016; 82: 747-751

(c) Georg Thieme Verlag KG

Stuttgart · New York .

ISSN 0032-0943

\section{Correspondence}

Hiroyuki Tanaka

Department of Pharmacognosy Graduate School of Pharmaceutical Sciences

Kyushu University

3-1-1 Maidashi, Higashi-ku

Fukuoka 812-8582

Japan

Phone: + 81926426581

Fax: + 81926426581

htanaka@phar.kyushu-u.ac.jp

\section{$\nabla$}

Medicinal mushrooms belonging to the genus Ganoderma (Ganodermataceae) are known as "Lingzhi" and "Reishi" in China and Japan, respectively. They are a group of wood-degrading mushrooms with hard fruiting bodies comprising a pileus, spore, and stipe [1]. For over a century, Ganoderma species extracts have been traditionally used as a Chinese medicinal mushroom for the treatment of hepatitis $[2,3]$, cancer-related fatigue and immune functions [4,5], neurasthenia [6], and cancer [7], where Ganoderma extract has been shown to have anticancer activity against MCF-7 and MDA-MB-231 breast cancer cells [8, 9], 95-D lung cancer cells [10], PC-3 prostate cancer cells [9], and HUC-PC and MTC-11 bladder cancer cells [11]. To date, more than 100 ganoderic

\footnotetext{
* These authors contributed equally to this work.
}

body; the best extraction efficiency was found when $50 \%$ ethanol was used, which suggests the use of a strong liquor to completely harness the potential of Ganoderma triterpenoids in daily life.

\section{Abbreviations \\ $\nabla$ \\ BSA: bovine serum albumin \\ CRs: cross-reactivities \\ $\mathrm{CV}$ : coefficient of variation \\ GAA: ganoderic acid A \\ icELISA: indirect competitive enzyme-linked immunosorbent assay \\ MAb: monoclonal antibody \\ OVA: ovalbumin}

Supporting information available online at http://www.thieme-connect.de/products acids, a kind of highly oxygenated C30 lanostanetype triterpenoid, have been isolated from Ganoderma species [1] and they were active forms that exert various pharmacological activities, as mentioned above. Among them, GAA ( $\bullet$ Fig. 1 ) is of great interest as it is abundantly present in Ganoderma species $[12,13]$. It has also been reported to suppress the growth and invasive behavior of the human breast cancer cell line MDA-MB-231. This is accomplished through the downregulation of the expression of cyclin-dependent kinase 4, which regulates the $G_{1} / G_{0}$ phase in the cell cycle, and through the inhibition of activator protein-1/ nuclear factor- $k \mathrm{~B}$-dependent secretion of urokinase-type plasminogen activators, which control cell adhesion and migration [14]. Furthermore, GAA enhances the chemosensitivity of the HepG2 human liver cancer cells to cisplatin through the inhibition of IL-6-induced signal transducers and the activation of transcription 3 phosphorylation in HepG2 cells via suppression of JAK1 and JAK2 
[15]. Since Ganoderma species are currently used worldwide as dietary supplements, pharmacokinetic studies of GAA after oral administration have recently received attention $[16,17]$. In addition, quality control of commercially available Ganoderma is an important subject as its quality directly affects the potential activity of Ganoderma in natural and traditional medicines.

Herein, we produced an MAb against GAA (MAb $12 \mathrm{~A}$ ) and developed an icELISA for the detection of GAA in Ganoderma lingzhi (Ganodermataceae), which is commercially cultivated and is available throughout East Asia [18]. Systematic characterization of MAb $12 \mathrm{~A}$ via ELISA revealed that it has high specificity against GAA and exhibits high sensitivity toward GAA with an LOD of $6.10 \mathrm{ng} / \mathrm{mL}$. Several validation analyses support the accuracy and reliability of the developed icELISA method for the quantitative analysis of GAA in Ganoderma. The production, characterization, and application of MAb $12 \mathrm{~A}$ are described in this study. Moreover, the variation in GAA content of the different parts of G. lingzhi as well as the optimal ethanol concentration for preparing extracts are discussed in this study.

\section{Results and Discussion}

Titers of antibodies in serum obtained from BALB/c mice hyperimmunized by GAA-BSA conjugates were investigated by indirect ELISA. The antibody titer against GAA-OVA conjugates increased as the booster number increased, suggesting that the GAA-BSA conjugates worked as immunogens; however, Erlanger reported that the optimal hapten number is between 8 and 25 molecules for BSA conjugates [19]. After performing cell fusion of splenocytes with myeloma cells using the polyethylene glycol (PEG) method and subsequent screening through limited dilution methods, one hybridoma cell line $(12 \mathrm{~A})$ producing MAb reactive to GAA was obtained.

An isotyping test using an IsoStrip Mouse Monoclonal Antibody Isotyping Kit (Roche Diagnostics) revealed that MAb $12 \mathrm{~A}$ was classified as IgG1, which have $k$ light chains. After MAb 12 A was purified from the supernatant of selected hybridoma clone $12 \mathrm{~A}$ using a Protein G FF column, the purity of MAb 12 A was determined to be $76.8 \%$ through the method proposed by Bradford using a pure mouse IgG goat antibody as a standard protein [20]. Characterization of MAb 12 A was mainly performed using ELISA. Primarily, the reactivity of MAb 12 A against GAA-OVA conjugates $(2 \mu \mathrm{g} / \mathrm{mL})$ was analyzed by indirect ELISA to optimize their concentration for further icELISA. The reactivity response curve drawn by plotting absorbance against the logarithm of the MAb 12 A concentration revealed that MAb 12 A reacts with GAA-OVA conjugates in a concentration-dependent manner ( $\bullet$ Fig. 2). When the concentrations of MAb 12 A for icELISA were evaluated with an absorbance of appropriately 1.0 at $405 \mathrm{~nm}, 500 \mathrm{ng} / \mathrm{mL}$ was found to be the optimal concentration for the primary antibody. Subsequently, icELISA was performed to investigate the inhibitory activity of MAb $12 \mathrm{~A}$ against free GAA. Serially double-diluted concentrations of free GAA were incubated with MAb $12 \mathrm{~A}$ ( $500 \mathrm{ng} / \mathrm{mL}$ ). Competitive binding was observed for the MAb $12 \mathrm{~A}$ bound to either free GAA or the GAA-OVA conjugates adsorbed on the immunoplate. The increased free GAA led to a decrease in the amount of MAb 12 A that was able to bind to the GAA-OVA conjugates, and vice versa; therefore, the absorbance decreased as the MAb 12 A concentration increased in a logarithmic manner. The icELISA revealed that the $\mathrm{IC}_{50}$ and detectable range of GAA are $37.6 \mathrm{ng} / \mathrm{mL}$ and $6.10-195 \mathrm{ng} / \mathrm{mL}$, respectively ( Fig. 3).
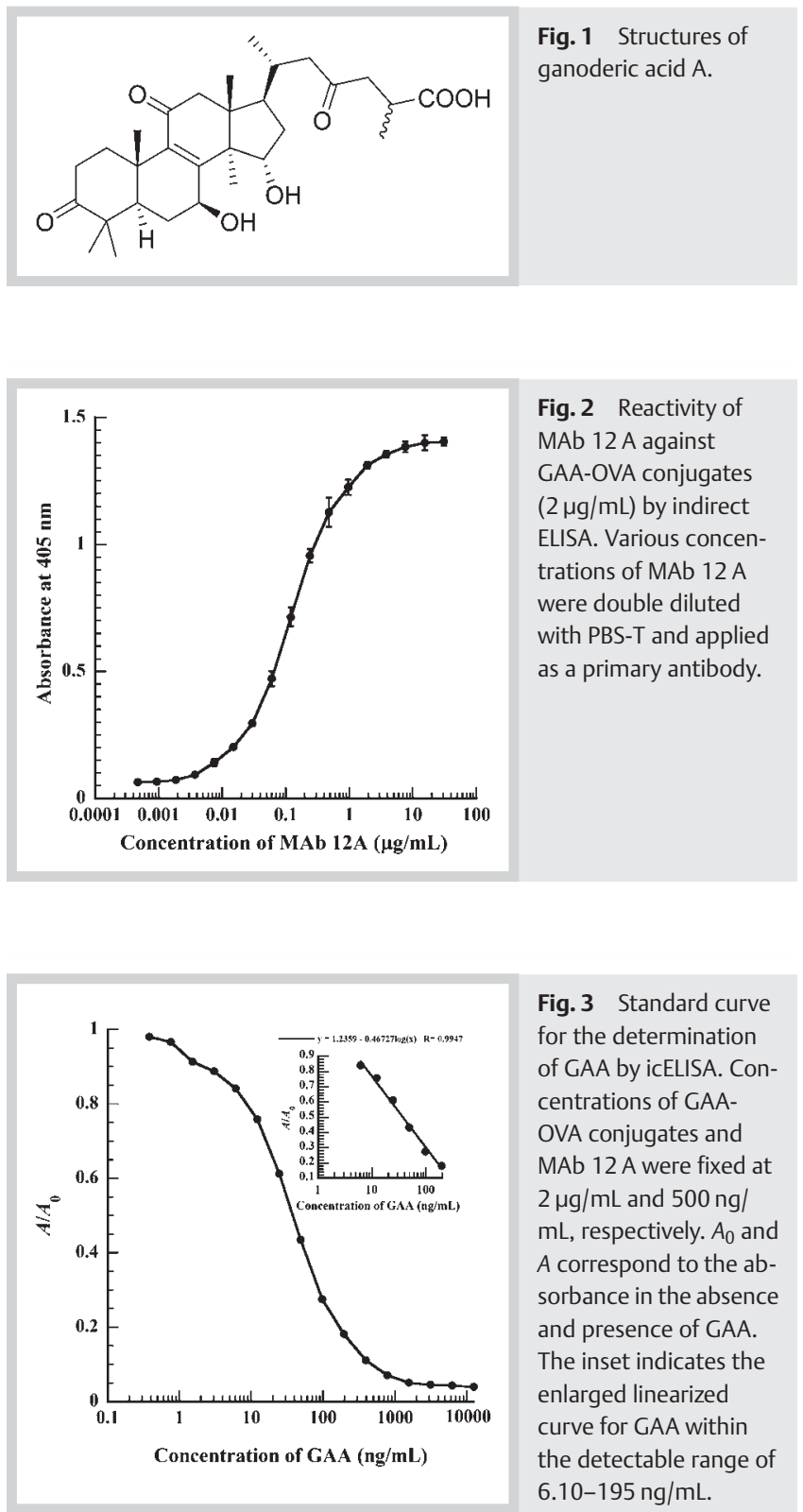

Recently, LC-MS/MS has been developed to investigate the pharmacokinetics and oral bioavailability of GAA with a lower LOD of $0.50 \mathrm{ng} / \mathrm{mL}$ [16] and $5.83 \mathrm{ng} / \mathrm{mL}$ [17]. Although the LOD obtained in the icELISA is slightly higher than that of the LC-MS/MS system, the LOD is sufficient for the determination of GAA in Ganoderma.

CRs of antibodies are the most important factor influencing the accuracy of the quantitative analysis when icELISA is developed. Since Ganoderma contains large amounts of C30 lanostane-type triterpenoids, CRs against structure-related compounds need to be evaluated; the CRs against each compound were calculated using the ratio of $\mathrm{IC}_{50}$ of GAA to that of the test compounds. Therefore, 32 types of Ganoderma triterpenoids were selected as test compounds ( Table 1). The results revealed that MAb $12 \mathrm{~A}$ possesses high selectivity to GAA as the highest CRs were obtained from ganoderenic acid A with CRs of 3.69\%. The difference between GAA and ganoderenic acid $\mathrm{A}$ is the presence of a double bond at $C^{20,22}$, which suggests that MAb 12 A can specifically recognize GAA molecules with only a slight difference between the 
Table 1 CRs of the MAb $12 \mathrm{~A}$ against structure-related compounds.

\begin{tabular}{|c|c|c|}
\hline Class & Compound & Cross-reactivity (\%) \\
\hline \multirow{25}{*}{$\begin{array}{l}\text { C30 lanostanes } \\
\text { (Ganoderic acids) }\end{array}$} & ganoderic acid A & 100.00 \\
\hline & ganoderic acid AM1 & $<0.1$ \\
\hline & ganoderic acid B & $<0.1$ \\
\hline & ganoderic acid C1 & 0.15 \\
\hline & ganoderic acid C2 & 0.42 \\
\hline & ganoderic acid C6 & $<0.1$ \\
\hline & ganoderic acid DM & 0.17 \\
\hline & ganoderic acid E & $<0.1$ \\
\hline & ganoderic acid H & $<0.1$ \\
\hline & ganoderic acid $\mathrm{K}$ & 0.22 \\
\hline & ganoderic acid LM2 & $<0.1$ \\
\hline & ganoderic acid N & $<0.1$ \\
\hline & ganoderic acid S & $<0.1$ \\
\hline & ganoderic acid SZ & $<0.1$ \\
\hline & ganoderic acid TN & $<0.1$ \\
\hline & ganoderic acid T-Q & $<0.1$ \\
\hline & ganoderic acid TR & 2.21 \\
\hline & ganoderic acid $Y$ & $<0.1$ \\
\hline & ganoderic acid $\zeta$ & $<0.1$ \\
\hline & ganolucidic acid A & $<0.1$ \\
\hline & ganoderenic acid A & 3.69 \\
\hline & ganoderenic acid C & $<0.1$ \\
\hline & ganoderenic acid D & 0.14 \\
\hline & ganoderenic acid F & 1.07 \\
\hline & ganoderenic acid H & $<0.1$ \\
\hline \multirow{5}{*}{$\begin{array}{l}\text { C30 lanostanes } \\
\text { (alcohols) }\end{array}$} & ganodermanondiol & $<0.1$ \\
\hline & ganodermanontriol & $<0.1$ \\
\hline & ganoderol A & $<0.1$ \\
\hline & ganoderol B & $<0.1$ \\
\hline & ganoderiol F & $<0.1$ \\
\hline \multirow{2}{*}{$\begin{array}{l}\text { C30 lanostanes } \\
\text { (aldehydes) }\end{array}$} & lucialdehyde A & $<0.1$ \\
\hline & lucialdehyde B & $<0.1$ \\
\hline
\end{tabular}

single and double bonds on the side chain. The results of the CRs test raised the possibility that MAb $12 \mathrm{~A}$ can be instrumental for the detection of GAA in Ganoderma.

To confirm the accuracy of the developed icELISA for the detection of GAA, the intra- and inter-assay precisions were investigated using six detectable ranges of GAA $(6.10,12.2,24.4,48.8$, 97.5 , and $195 \mathrm{ng} / \mathrm{mL}$ ). To determine the intra-assay precision, the $C V$ values were obtained between wells $(n=6)$ of the same plate, whereas these values were obtained from different plates $(n=3)$ for the inter-assay precision. These results show that the maximum CV for the intra-assay precision is $5.95 \%$, whereas that for the inter-assay precision is $7.97 \%$ (@ Table 2). All CV values were $<10 \%$, indicating that the developed icELISA using MAb 12 A possesses high accuracy ( $\bullet$ Table 2 ).

To further evaluate the reliability of the developed icELISA, the correlation of the GAA content in G. lingzhi extracts determined by both icELISA and HPLC was investigated. For these samples, extracts were prepared from three parts (pileus, stipe, and spore) of the fruiting body using various concentrations of ethanol ( 0 , $25,50,75$, and $100 \%$ ) to assess the effect of the ethanol concentration on the extraction efficiency of GAA. Since Ganoderma has been traditionally consumed as liquor for a long time in China, investigation of the extraction efficiency for bioactive Ganoderma triterpenoids by variation of the ethanol concentration is of great interest in the field of natural and traditional medicines [21]. - Fig. 4 shows the results of the comparative analysis of GAA between icELISA and HPLC, wherein the two data sets showed a
Table 2 Intra- and inter-assay precision analysis based on CV for determination of GAA by icELISA using MAb $12 \mathrm{~A}$.

\begin{tabular}{|cll|}
\hline $\begin{array}{c}\text { Concentration of GAA } \\
\text { (ng/mL) }\end{array}$ & $\begin{array}{l}\mathbf{C V} \text { (\%) } \\
\text { Intra-assay }(\mathbf{n}=\mathbf{6})\end{array}$ & Inter-assay $(\mathbf{n = 3})$ \\
\hline 6.10 & 1.59 & 1.93 \\
\hline 12.2 & 5.95 & 0.75 \\
\hline 24.4 & 2.79 & 5.57 \\
\hline 48.8 & 4.40 & 5.99 \\
\hline 97.5 & 2.06 & 4.31 \\
\hline 195 & 3.52 & 7.97 \\
\hline
\end{tabular}

All values represent the mean \pm standard deviation (S. D.) for three plates and six replicate wells for each concentration within one plate

Table 3 Determination of GAA prepared from three different parts (pileus, stipe, and spore) using different ethanol concentrations $(0,25,50,75$, and $100 \%$ ) by developed icELISA using MAb $12 \mathrm{~A}$.

\begin{tabular}{|c|c|c|}
\hline $\begin{array}{l}\text { Ethanol } \\
\text { concentration (\%) }\end{array}$ & Sample parts & $\begin{array}{l}\text { Concentration of GAA } \\
\text { (\% w/w in dry weight) }\end{array}$ \\
\hline \multirow[t]{3}{*}{100} & Pileus & $3.368 \pm 0.257$ \\
\hline & Stipe & $0.233 \pm 0.022$ \\
\hline & Spore & $0.098 \pm 0.007$ \\
\hline \multirow[t]{3}{*}{75} & Pileus & $3.343 \pm 0.280$ \\
\hline & Stipe & $0.360 \pm 0.018$ \\
\hline & Spore & $0.130 \pm 0.007$ \\
\hline \multirow[t]{3}{*}{50} & Pileus & $3.376 \pm 0.242$ \\
\hline & Stipe & $0.249 \pm 0.025$ \\
\hline & Spore & $0.120 \pm 0.003$ \\
\hline \multirow[t]{3}{*}{25} & Pileus & $1.417 \pm 0.297$ \\
\hline & Stipe & $0.258 \pm 0.038$ \\
\hline & Spore & $0.130 \pm 0.039$ \\
\hline \multirow[t]{3}{*}{0} & Pileus & $1.085 \pm 0.219$ \\
\hline & Stipe & $0.172 \pm 0.009$ \\
\hline & Spore & $0.099 \pm 0.012$ \\
\hline
\end{tabular}

All values are the mean \pm standard deviation (S. D.) from triplicate samples

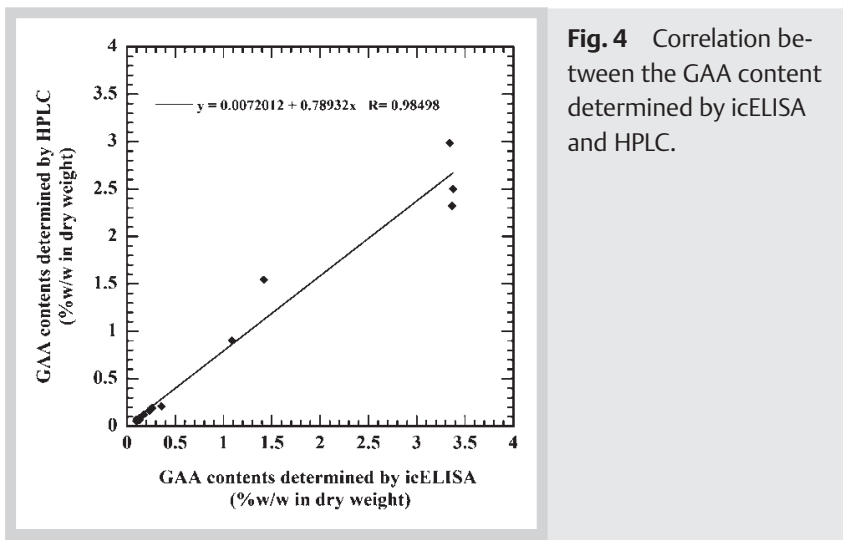

good positive correlation with a coefficient of determination of 0.98. This indicates that the developed icELISA using MAb $12 \mathrm{~A}$ provides accurate and reliable detection of GAA. O Table 3 summarizes the results of the quantitative analysis of GAA prepared from different parts using different ethanol concentrations with icELISA. Consequently, the pileus was found to contain the highest amount of GAA, followed by the stipe and spore; this order was not affected by the ethanol concentration. Interestingly, GAA content in the pileus dramatically decreased when $25 \%$ 
ethanol was used to prepare the extracts, whereas those in the stipe and spore remained nearly constant over the entire range of ethanol concentrations. These results imply that the effect of the ethanol concentration on the extraction efficiency was observed when more than $50 \%$ ethanol was used for the extraction of GAA.

In this study, we produced a GAA-specific MAb (MAb 12 A) and applied it to icELISA for the detection of GAA in G. lingzhi. To date, LC-MS has been used for the detection of GAA in pharmacokinetic studies $[16,17]$. However, this technique requires labor-intensive and complicated pretreatment of the sample prior to analysis. The main advantages of ELISA are that it is cost-effective, rapid, and simple. Moreover, many samples can be analyzed without the need for pretreatment, and the developed icELISA combines both sensitivity and specificity for GAA. Considering that GAA is one of the major Ganoderma triterpenoids in commercially available G. lingzhi [12] and G. lucidum [13] in the market, a developed icELISA would be useful for quality control, where GAA content is used as an index.

Furthermore, our study revealed that more than $50 \%$ ethanol is effective and suitable for the extraction of GAA, suggesting that the use of strong liquor is recommended to completely harness the potential of Ganoderma triterpenoids in daily life.

\section{Materials and Methods}

$\nabla$

\section{Chemicals and reagents}

GAA ( $\geq 99 \%$ ) was purchased from ChromaDex. BSA ( $\geq 97 \%$ ) and albumin from chicken egg whites (OVA; $\geq 99 \%$ ) were obtained from Sigma-Aldrich. Freund's complete and incomplete adjuvants were purchased from Difco. RPMI 1640-Dulbecco's-Ham's F12 (eRDF) medium and RD-1 additives were obtained from Kyokuto Pharmaceutical Industrial Co. Goat F(ab) anti-mouse IgG H\&L (HRP) (ab6823) and pure mouse IgG goat antibody were purchased from Abcam and MP Biomedicals, respectively. All other chemicals were standard analytical reagent grade commercial products.

\section{Sample preparation}

G. lingzhi was identified and provided by Ken Sawai and Takeshi Sawai. Dried G. lingzhi was divided into three parts (pileus, stipe, and spore), ground using a crusher, and sifted using a $0.56-\mathrm{mm}$ mesh. Constant amounts (50 mg) of sifted powder were then measured and a fraction containing ganoderic acids was prepared by sonication in various ethanol concentrations [100, 75 , 50,25 , and $0 \%(v / v), 1.0 \mathrm{~mL}$ ] for $30 \mathrm{~min}$. This was then collected in a small test tube after centrifugation at $12000 \mathrm{rpm}$ for $10 \mathrm{~min}$ at room temperature. This extraction step was repeated five times and the combined extracted solution $(5.0 \mathrm{~mL})$ was evaporated at $60{ }^{\circ} \mathrm{C}$ to dryness. The residue was redissolved in $1.0 \mathrm{~mL}$ of methanol and centrifuged at $12000 \mathrm{rpm}$ for $1 \mathrm{~min}$. The resulting supernatant was then diluted appropriately for both ELISA and HPLC analyses.

\section{Production of a monoclonal antibody} against ganoderic acid $\mathrm{A}$ (MAb $12 \mathrm{~A}$ )

Five-week-old male BALB/c mice were purchased from KBT Oriental Co. Their standard diet (MF; Oriental Yeast Co.) and water were provided ad libitum. All experimental procedures and care were approved by the Committee on the Ethics of Animal Experiments (approval number A26-013-0) of the Graduate School of
Pharmaceutical Sciences, Kyushu University, and were performed following the Guidelines for Animal Experiments of the Graduate School of Pharmaceutical Sciences, Kyushu University. MAb 12 A was produced through immunization of GAA-BSA conjugates into male BALB/c mice every two weeks, as previously described [22]. For the first and second immunizations, Freund's complete and incomplete adjuvants were mixed, respectively, with GAA-BSA conjugates and immunized as an emulsion into the abdominal cavity of the BALB/c mice with $50 \mu \mathrm{g}$ of GAA-BSA conjugates. A subsequent booster was performed three times with $100 \mu \mathrm{g}$ of GAA-BSA conjugates. On the fourth day after the final booster, the splenocytes were fused with mice myeloma SP2/0 cells using PEG. They were then selected using hypoxanthine-aminopterin-thymidine (HAT) medium, which comprises eRDF medium supplemented with RD-1 additives and 10\% (v/v) fetal calf serum (FCS; Gibco-Invitrogen). The resultant hybridomas producing the anti-GAA antibody were then cloned by the limited dilution method and were selected by indirect and indirect competitive ELISAs (icELISA). Selected hybridomas (12 A) were then cultured in the HT selective medium $(600 \mathrm{~mL})$ without FCS.

Purification of MAb 12 A was performed using a Protein G FF column $(0.46 \times 11 \mathrm{~cm}$, Pharmacia Biotech). The supernatant of the culture medium $(600 \mathrm{~mL})$ was collected by centrifugation at $1800 \mathrm{rpm}$ for $5 \mathrm{~min}$ and filtered using a bottle-top filter $(0.2 \mu \mathrm{m}$ polyethersulfone membrane, Nalgene, Thermo Fisher Scientific). The $\mathrm{pH}$ supernatant containing MAb $12 \mathrm{~A}$ was adjusted to a $\mathrm{pH}$ of 7.0 with $1 \mathrm{M}$ Tris- $\mathrm{HCl}$ solution ( $\mathrm{pH} 9.0$ ) and applied to the column equilibrated with $10 \mathrm{mM}$ phosphate buffer ( $\mathrm{pH}$ 7.0). After washing the column with $10 \mathrm{mM}$ phosphate buffer ( $\mathrm{pH} 7.0$ ), adsorbed IgG was eluted with $100 \mathrm{mM}$ citrate buffer ( $\mathrm{pH}$ 3.0) and collected in test tubes containing $1 \mathrm{M}$ Tris- $\mathrm{HCl}$ solution ( $\mathrm{pH} 9.0$ ) for neutralization. The elution of MAb $12 \mathrm{~A}$ was evaluated by its absorbance at $280 \mathrm{~nm}\left(\mathrm{OD}_{280}\right)$. The fraction with $\mathrm{OD}_{280}$ over 0.3 was collected, concentrated, dialyzed three times against distilled water at $4{ }^{\circ} \mathrm{C}$ with $6 \mathrm{~h}$ intervals, and lyophilized to give $18.3 \mathrm{mg}$ of MAb $12 \mathrm{~A}$.

The purity of MAb $12 \mathrm{~A}$ was calculated according to the method proposed by Bradford using pure mouse IgG goat antibody as a standard [20].

\section{Indirect ELISA and icELISA using MAb $12 \mathrm{~A}$}

The reactivity of MAb $12 \mathrm{~A}$ against coated antigen, GAA-OVA conjugates, and free antigen, GAA, was evaluated by indirect ELISA and icELISA, respectively. For indirect ELISA, GAA-OVA conjugates $(2 \mu \mathrm{g} / \mathrm{mL})$ were immobilized on a 96-well immunoplate (Nunc, Maxisorb) in $50 \mathrm{mM}$ carbonate buffer (pH 9.6, $100 \mu \mathrm{L} /$ well) through incubation for $1 \mathrm{~h}$. The plate was then blocked with PBS containing 5\% (w/v) skimmed milk (PBS-sm; $300 \mu \mathrm{L} /$ well) for $1 \mathrm{~h}$ to avoid nonspecific adsorption of other proteins. Subsequently, various concentrations of MAb $12 \mathrm{~A}$ solution $(100 \mu \mathrm{L} /$ well $)$ in PBS containing $0.05 \%(\mathrm{v} / \mathrm{v})$ Tween 20 (PBS-T) were then incubated with immobilized GAA-OVA conjugates for $1 \mathrm{~h}$. Next, MAb $12 \mathrm{~A}$ binding to the immobilized GAA-OVA conjugates were reacted with a 5000-fold diluted secondary antibody, goat $\mathrm{F}(\mathrm{ab})$ anti-mouse IgG H\&L (HRP) $(100 \mu \mathrm{L} /$ well), for $1 \mathrm{~h}$, followed by a substrate solution composed of $0.3 \mathrm{mg} / \mathrm{mL} \mathrm{2,2'-azino-bis(3-eth-}$ ylbenzothiazoline-6-sulfonic acid) diammonium salt (ABTS) in $0.1 \mathrm{M}$ citrate buffer ( $\mathrm{pH} 4.0$ ) supplemented with $0.003 \%(\mathrm{v} / \mathrm{v})$ $\mathrm{H}_{2} \mathrm{O}_{2}(100 \mu \mathrm{L} /$ well $)$ for $15 \mathrm{~min}$ to develop color.

The difference between indirect ELISA and icELISA is the primary antibody step following the blocking step. In icELISA, evaluation 
of the competitive activity of MAb 12 A against free GAA or GAA of GAA-OVA conjugates is necessary. Thus, various free GAAs $(50 \mu \mathrm{L} /$ well $)$ in $10 \%(\mathrm{v} / \mathrm{v})$ methanol were incubated with MAb 12 A solution $(50 \mu \mathrm{L} /$ well $)$ in PBS-T for $1 \mathrm{~h}$.

The incubation steps of both indirect and icELISA were performed at $37^{\circ} \mathrm{C}$ and washing between each step was performed three times using PBS-T. The absorbance at $405 \mathrm{~nm}$ was measured using a microplate reader (Multiskan ${ }^{\mathrm{TM}}$ FC Microplate Photometer, Thermo Fisher Scientific, Inc.). The CRs of MAb 12 A against structure-related compounds were investigated by the following equation [23]:

CRs $(\%)=\frac{\mathrm{IC}_{50} \text { for GAA }}{\mathrm{IC}_{50} \text { for compound under investigation }} \times 100$

\section{HPLC analysis}

HPLC analysis was performed using a Gilson 805 Manometric Module pump connected to an SPD-20 A Shimadzu Prominence UV/VIS detector ( $254 \mathrm{~nm}$ ) and an HP ProBook $4230 \mathrm{~S}$ computer. A COSMOSIL-packed 5C 18 -AR-II column $(4.6 \times 150 \mathrm{~mm}, 5 \mu \mathrm{m}$ particle size, Nacalai Tesque) was used. As for the mobile phase, $30 \%$ $(\mathrm{v} / \mathrm{v})$ acetonitrile prepared with water containing $0.1 \%(\mathrm{v} / \mathrm{v})$ acetic acid was used at a flow rate of $1.0 \mathrm{~mL} / \mathrm{min}$. Calibration curves for GAA were constructed in the concentration range of 10$1000 \mu \mathrm{g} / \mathrm{mL}$. Analyses of the samples were performed in triplicate.

\section{Supporting information}

The section for synthesis of GAA-BSA and GAA-OVA conjugates, and determination of the hapten number are available as Supporting Information.

\section{Acknowledgements}

We thank Ken Sawai and Takeshi Sawai (Toyotanshien Co Ltd., Sapporo, Japan) for providing G. lingzhi for the manuscript. This work was supported by a Grant-in-Aid for Challenging Exploratory Research [26660147] of the Japan Society for the Promotion of Science (JSPS).

\section{Conflict of Interest}

$\nabla$

The authors declare no competing financial interests.

\section{References}

1 Baby S, Johnson AJ. Govindan B. Secondary metabolites from Ganoderma. Phytochemistry 2015; 114: 66-101

2 Li YQ Wang SF. Anti-hepatitis B activities of ganoderic acid from Ganoderma lucidum. Biotechnol Lett 2002; 28: 837-841

3 Gao Y, Zhou S, Chen G, Dai X, Ye J, Gao H. A phase I/II study of a Ganoderma lucidum (Curt.: Fr.) P. Karst. (Ling Zhi, Reishi Mushroom) extract in patients with chronic hepatitis B. Int J Med Mushrooms 2002; 4: 321 327
4 Zhao H, Zhang $Q$, Zhao L, Huang X, Wang J, Kang X. Spore Powder of Ganoderma lucidum Improves Cancer-Related Fatigue in Breast Cancer Patients Undergoing Endocrine Therapy: A Pilot Clinical Trial. Evid Based Complement Alternat Med 2012; 2012: 809614

5 Gao Y, Zhou S, Jiang W, Huang M, Dai X. Effects of ganopoly (a Ganoderma lucidum polysaccharide extract) on the immune functions in advanced-stage cancer patients. Immunol Invest 2003; 32: 201-215

6 Tang W, Gao Y, Chen G, Gao H, Dai X, Ye J, Chan E, Huang M, Zhou S. A randomized, double-blind and placebo-controlled study of a Ganoderma lucidum polysaccharide extract in neurasthenia. J Med Food 2005; 8: 53-58

7 Sliva D. Ganoderma lucidum (Reishi) in cancer treatment. Integr Cancer Ther 2003; 2: 358-364

$8 \mathrm{Hu}$ H, Ahn NS, Yang X, Lee YS, Kang KS. Ganoderma lucidum extract induces cell cycle arrest and apoptosis in MCF-7 human breast cancer cell. Int J Cancer 2002; 102: 250-253

9 Sliva D, Labarrere C, Slivova V, Sedlak M, Lloyd jr. FP, Ho NW. Ganoderma lucidum suppresses motility of highly invasive breast and prostate cancer cells. Biochem Biophys Res Commun 2002; 298: 603-612

10 Tang W, Liu JW, Zhao WM, Wei DZ, Zhong JJ. Ganoderic acid T from Ganoderma lucidum mycelia induces mitochondria mediated apoptosis in lung cancer cells. Life Sci 2006; 80: 205-211

11 Lu QY, Jin YS, Zhang Q Zhang Z, Heber D, Go VL, Li FP, Rao JY. Ganoderma lucidum extracts inhibit growth and induce actin polymerization in bladder cancer cells in vitro. Cancer Lett 2004; 216: 9-20

12 Liu J, Kurashiki K, Fukuta A, Kaneko S, Suimi Y, Shimizu K, Kondo R. Quantitative determination of the representative triterpenoids in the extracts of Ganoderma lucidum with different growth stages using high-performance liquid chromatography for evaluation of their $5 \alpha$ reductase inhibitory properties. Food Chem 2012; 133: 1034-1038

13 Zhao J, Zhang XQ Li SP, Yang FQ Wang YT, Ye WC. Quality evaluation of Ganoderma through simultaneous determination of nine triterpenes and sterols using pressurized liquid extraction and high performance liquid chromatography. J Sep Sci 2006; 29: 2609-2615

14 Jiang J, Grieb B, Thyagarajan A, Sliva D. Ganoderic acids suppress growth and invasive behavior of breast cancer cells by modulating AP-1 and NF-kappaB signaling. Int J Mol Med 2008; 21: 577-584

15 Yao X, Li G, Xu H, Lü C. Inhibition of the JAK-STAT3 signaling pathway by ganoderic acid A enhances chemosensitivity of HepG2 cells to cisplatin. Planta Med 2012; 78: 1740-1748

16 Teekachunhatean S, Sadja S, Ampasavate C, Chiranthanut N, Rojanasthien N, Sangdee C. Pharmacokinetics of ganoderic acids A and F after oral administration of ling zhi preparation in healthy male volunteers. Evid Based Complement Alternat Med 2012; 2012: 780892

17 Jin ZH, Wang YR, Ren XQ Xie HR, Gao YY, Wang L, Gao SC. Pharmacokinetics and oral bioavailability of ganoderic acid $A$ by high performance liquid chromatography-tandem mass spectrometry. Int J Pharm 2015; 11: $27-34$

18 Cao Y, Wu SH, Dai YC. Species clarification of the prize medicinal Ganoderma mushroom "Lingzhi". Fungal Divers 2012; 56: 49-62

19 Erlanger $B F$. The preparation of antigenic hapten-carrier conjugates: a survey. Methods Enzymol 1980; 70: 85-104

20 Bradford MM. A rapid and sensitive method for the quantitation of microgram quantities of protein utilizing the principle of protein-dye binding. Anal Biochem 1976; 72: 248-254

21 Liu J, Shimizu K, Tanaka A, Shinobu W, Ohnuki K, Nakamura T, Kondo R. Target proteins of ganoderic acid DM provides clues to various pharmacological mechanisms. Sci Rep 2012; 2: 905

22 Sakata R, Shoyama Y, Murakami H. Production of monoclonal antibodies and enzyme immunoassay for typical adenylate cyclase activator, Forskolin. Cytotechnology 1994; 16: 101-108

23 Weiler EW, Zenk MH. Radioimmunoassay for the determination of digoxin and related compounds in Digitalis lanata. Phytochemistry 1976; 15: 1537-1545 